\title{
Mechanistic modelling of cyclic voltage-capacity response for lithium-ion batteries
}

\author{
Marko Nagodea ${ }^{a}$ Aleš Gosar ${ }^{b}$, Caoimhe A. Sweeneyc ${ }^{c}$ Joris Jaguemont ${ }^{d}$, Joeri Van \\ Mierloe $^{\mathrm{e}}$ Domen Šerugaf ${ }^{\mathrm{f}, \mathrm{corr}}$
}

\begin{abstract}
a E-mail address: marko.nagode@fs.uni-lj.si, Address: University of Ljubljana, Faculty of Mechanical Engineering, Askerceva 6 1000 Ljubljana Slovenia, Telephone: +386 14771507

b E-mail address: ales.gosar@fs.uni-lj.si, Address: University of Ljubljana, Faculty of Mechanical Engineering, Askerceva 6 1000 Ljubljana Slovenia, Telephone: +386 14771176

c E-mail address: caoimhe.sweeney@siemens.com, Address: Siemens PLM Software Inc., Interleuvenlaan 68 B-3001 Leuven Belgium, Telephone: +3216384 477

d E-mail address: joris.jaguemont@vub.be, Address: Vrije Universiteit Brussel, Pleinlaan 2, 1050 Brussels Telephone: +32 2 6292803

e E-mail address: joeri.van.mierlo@vub.be, Address: Vrije Universiteit Brussel, Pleinlaan 2, 1050 Brussels Telephone: +32 2 6292803

f,corr E-mail address: domen.seruga@fs.uni-lj.si, Address: University of Ljubljana, Faculty of Mechanical Engineering, Askerceva 61000 Ljubljana Slovenia, Telephone: +386 14771743
\end{abstract}

\section{Abstract}

One of the challenging tasks related to lithium-ion batteries (LIBs) remains a comprehensive approach for battery behaviour modelling. An approach is presented that enables modelling the voltage-capacity response of LIBs that are subjected to variable temperature and current load histories. A detailed presentation of the developed macro-scale phenomenological model embedding the mechanistic properties of the Prandtl type hysteresis operator and the concept of the force-voltage analogy is made. The necessary input data preparation for the model calibration is also presented. Accuracy of the model is confirmed with experimental observations for both nested current load history at two different temperatures and for arbitrary current load history. The same measured data is used to calibrate and to simulate response of the first order Thevenin equivalent circuit topology in order to amply compare the obtained results. 


\section{Highlights}

A current controlled macro-scale model of lithium-ion battery is proposed.

Battery behaviour under arbitrary cyclic loading could be simulated.

A detailed calculation algorithm of the model is presented.

Input data preparation is described thoroughly.

The model validation is performed for various conditions demonstrating its accuracy.

\section{Keywords}

lithium-ion battery; continuum modelling; battery model; thermo-mechanical; Prandtl operator; cyclic loading 


\section{Nomenclature}

\begin{tabular}{|c|c|c|}
\hline Symbol & Unit & Definition \\
\hline$C$ & {$[/]$} & Charging mode \\
\hline$C_{1}$ & {$[\mathrm{~F}]$} & Parameter of the RC model \\
\hline$D$ & {$[/]$} & Discharging mode \\
\hline$I=I(t)$ & {$[\mathrm{A}]$} & Signed electric current \\
\hline$I_{\mathrm{IN}}$ & {$[\mathrm{A}]$} & Input electric current \\
\hline$L$ & {$[/]$} & Load history \\
\hline$q_{j}$ & {$[\mathrm{Ah}]$} & Yield capacity \\
\hline$q_{\zeta j, i}^{\mathrm{M}}$ & {$[\mathrm{Ah}]$} & $\begin{array}{l}\text { Charge }(M=C) \text { and discharge }(M=D) \text { branch back- } \\
\text { stresses }\end{array}$ \\
\hline$Q=Q(t)$ & {$[\mathrm{Ah}]$} & Electric charge \\
\hline$Q_{i}^{*}$ & {$[\mathrm{Ah}]$} & Corrected capacity \\
\hline$Q_{\mathrm{MIN}}$ & {$[\mathrm{Ah}]$} & Minimum experiment capacity \\
\hline$Q_{\mathrm{MAX}}$ & {$[\mathrm{Ah}]$} & Highest experiment capacity \\
\hline$Q_{\mathrm{MAX}}^{*}$ & {$[\mathrm{Ah}]$} & Reduced highest experiment capacity \\
\hline$R_{0}, R_{1}$ & {$[\Omega]$} & Parameters of the RC model \\
\hline$t_{i}$ & {$[\mathrm{~h}]$} & Time instant \\
\hline$T=T(t)$ & {$\left[{ }^{\circ} \mathrm{C}\right]$} & Temperature \\
\hline$u_{\mathrm{C} i}$ & {$[\mathrm{~V}]$} & Transitional charge voltage \\
\hline$u_{\mathrm{D} i}$ & {$[\mathrm{~V}]$} & Transitional discharge voltage \\
\hline$U=U(t)$ & {$[\mathrm{V}]$} & Electric voltage \\
\hline$U_{\mathrm{C} i}$ & {$[\mathrm{~V}]$} & Boundary charge voltages \\
\hline
\end{tabular}




\begin{tabular}{|c|c|c|}
\hline$U_{\mathrm{D} i}$ & {$[\mathrm{~V}]$} & Boundary discharge voltages \\
\hline$U_{\mathrm{OC}}$ & {$[\mathrm{V}]$} & Parameter of the RC model \\
\hline$U_{\text {OUT }}$ & {$[\mathrm{V}]$} & Measured output voltage \\
\hline$w_{\mathrm{C}}\left(Q_{i}\right)$ & {$[/]$} & Transitional charge function \\
\hline$w_{\mathrm{D}}\left(Q_{i}\right)$ & {$[/]$} & Transitional discharge function \\
\hline$\Delta I$ & {$[\mathrm{~A}]$} & Predetermined current history discretisation step \\
\hline$\Delta T$ & {$\left[{ }^{\circ} \mathrm{C}\right]$} & Predetermined temperature history discretisation step \\
\hline$\Delta U$ & {$[\mathrm{~V}]$} & Predetermined voltage history discretisation step \\
\hline$\Delta U_{\mathrm{C}}$ & {$[\mathrm{V}]$} & Charge voltage shift \\
\hline$\Delta U_{\mathrm{D}}$ & {$[\mathrm{V}]$} & Discharge voltage shift \\
\hline$\Delta t_{i}$ & {$[\mathrm{~h}]$} & Time increment \\
\hline$\zeta_{j}^{\mathrm{M}}(I, T)$ & {$\left[\mathrm{VA}^{-1} \mathrm{~h}^{-1}\right]$} & $\begin{array}{l}\text { Charge }(M=C) \text { and discharge }(M=D) \text { branch Prandtl } \\
\text { densities }\end{array}$ \\
\hline
\end{tabular}




\section{Introduction}

Heating and refrigeration systems, power tools, consumer electronics, industry machinery and various means of transportation are powered by electrical energy [1, 2]. As long as the use of electrical equipment is stationary or in a very narrow circumference, the energy can be gained from electrical wiring, e.g. a household. However, if electrical energy is needed at a distance, e.g. such as in the case of mobile phones or electric vehicles (EVs), then it has to be stored and available for use when and where required. A convenient storage of electrical energy is a rechargeable battery. Several kinds of chemistries could be used in a specific rechargeable battery, such as lead-acid, Nickel-Cadmium (NiCd), Nickel-metal hydride $(\mathrm{NiMH})$, Nickel-Zinc (NiZn) or lithium-ion, each having their own advantages and therefore their own target application [1-6]. In the last years, especially as the power source for mobile phones and EVs, lithium-ion batteries (LIB) have outrun the others, mostly due to their high energy density $[1,2,7,8]$. New types of batteries are still turning up, such as Sodium-ion based [9, 10] and solid-state type [11], but LIBs batteries are in use the most at present.

It is inevitable that new generations of EV's will soon be able to provide longer driving range [12], lower total purchase price, running and recycling costs $[13,14])$ and ease with recharging, as compared to the fossil fuel vehicles. Currently, individual LIB cells are connected into battery packs to increase the relatively small capacity or voltage of a single cell, so their capacity can vary from few Ah to several Ah $[15,16]$. This is already enough for an electric passenger car to cover distances comparable to traditional vehicles $[16,17]$. The main drawback is the relative large size and weight of the pack, which is also one of the most expensive components of an EV [18]. In addition, many safety concerns related to the structural integrity of the cell packs and the passenger safety during a crash $[19,20]$ as well as the potential long-term adverse effects of improper recycling of batteries on the environment [21] are still under investigation. 
EV batteries are exposed to various loading conditions governed by the driving patterns, essentially resulting in charge-discharge cycles. During cycling the battery gradually and permanently loses the capacity, up to the point e.g. a drop to 80 percent of its initial capacity, when it is no longer suitable to power the EV [18]. Various modelling philosophies and models have been proposed $[22,23]$ to simulate the behaviour or degradation of LIBs at different length scales. The classification of the models normally depends on the modelling strategy behind the individual model; hence, there are many classifications. A general one is to classify models as being electrochemical, equivalent circuit and hybrid [24]. Alternatively, models can also be classified as physical, empirical, semi-empirical, mathematical etc. Usually, models that address smaller size scales require more material parameters and meticulous experimental characterisation. For practical reasons the number of material parameters in these calculations should be small and the values of the material parameters should be effortlessly determinable. Electrochemical models like the pseudo two-dimensional model [25] or similar [26] provide theoretical principles to describe and to predict the actual reactions for degradation within the battery. Electrochemical models are essentially very theoretical and with multiple parameters, and are therefore often too complex for practical real-time application. Equivalent circuit models (ECMs) such as the Thevenin equivalent resistor-capacitor (RC) circuit models [27] and others [28] as well as hybrid models [29] are more empirical as compared to electrochemical models. ECMs are application oriented, and hence they require notably more experimental support and material data. In general, ECMs do not include the chemical structure and components within the battery or chemical reactions. Hybrids and semi-empirical models $[18,30]$ bridge the theoretical and experimentally oriented approaches by combining their advantages, i.e. semi-empirical models are designed to model specific characteristics of the cell while also being applicable to broader conditions as compared to empirical models. This makes semi-empirical models appealing for EV applications. To this end, mathematical approaches rely heavily on empirical equations, practical implementation of artificial neural network [31] and fuzzy logic [32], stochastic and abstract models [33] and also genetic algorithms [34]. Mathematical 
approaches are like semi-empirical models feasible for battery pack design and battery behaviour simulations.

One of the challenging tasks is a comprehensive approach for both battery voltage-capacity response modelling and fatigue damage calculation that would enable reliable lifetime predictions for any given load history of the LIB, e.g. forecast of number of charge/discharge cycles with an EV battery for a given driving profile until the capacity fade reaches the critical value. This remains an important issue as such fading effect can be observed with almost all battery chemistries [35]. This paper essentially addresses the first task - the battery behaviour modelling, namely the simulated voltage-capacity $(U-Q)$ response of the assumed load history, whilst providing the necessary grounds for the following fatigue analysis.

A novel, mechanistic approach for simulation of cyclic battery behaviour is presented. A new macro-scale phenomenological model composed of spring-slider segments of a Prandtl type was developed. The model can be used for simulations of cyclic voltage-capacity response of a LIB and other types of batteries as long as they exhibit monotonically increasing and decreasing charge and discharge curves, respectively. Voltage response could be simulated continuously for both arbitrary current and arbitrary temperature load history. The input data is minimised thus the required testing is substantially reduced. The approach was validated for several loading histories. Results were successfully compared against the actual LIB response. Furthermore, an additional comparison against the simulation using the first-order resistor-capacitor equivalent circuit model was carried out.

The rest of the paper is organised as follows. In Section 2, a detailed presentation of the developed operator-based approach is made, including a procedure to extract the necessary material data out of an experimental data set. The presentation of the initial calibration of the model by using a set of experimental data is made in Section 3. Examples that could serve 
as validation of the approach are presented in Section 4, while the final two sections are dedicated to discussion and conclusions.

\section{Method for battery voltage-capacity response modelling}

\subsection{The battery model}

The developed model consists of two independent spring-slider branches connected in parallel, controlling either charge or discharge behaviour of the battery (mechanistic approach to work out the electrical quantities). The model is schematically shown in Fig. 1. Its design was founded on a premise of the established conventional force-voltage analogy between mechanical and electrical systems [36], further on stress (force) is conveniently compared to electric potential difference or electric voltage $U=U(t)$, and strain (position) is related to capacity $Q=Q(t)$. Each branch of the model has properties of the Prandtl operator [37-39], providing the necessary capabilities for simulation of cyclic behaviour including the hysteresis phenomenon. Historically, the Prandtl operator was developed for modelling magnetic hysteresis [40]; however, the application of the operator is not limited only to magnetism as the hysteresis phenomenon can also be observed in other scientific disciplines like chemistry, biology, economics and engineering. For instance, Nagode et al. [38] used and modified the operator for continuous, temperature dependent stress-strain modelling and for cyclic damage evolution modelling [39, 41] of metals. In addition, it was shown recently [42] that by following movements of slider elements the operator can also be used for continuous calculation of the plastic strain energy density and fatigue life prediction of linear or nonlinear elastic solids [43]. Here, the model is adapted to work with the selected electrical quantities, i.e. temperature dependent voltage-capacity response.

The model in the presented form is current-controlled. Time $t$, signed current $I=I(t)$, for which the corresponding capacity is calculated, and temperature $T=T(t)$ are required as input quantities, whilst voltage is the output quantity. The necessary experimental support is 
therefore completely minimised. Both the complete developed calculation procedure and the basics of the required input data preparation are explained in detail hereinafter.

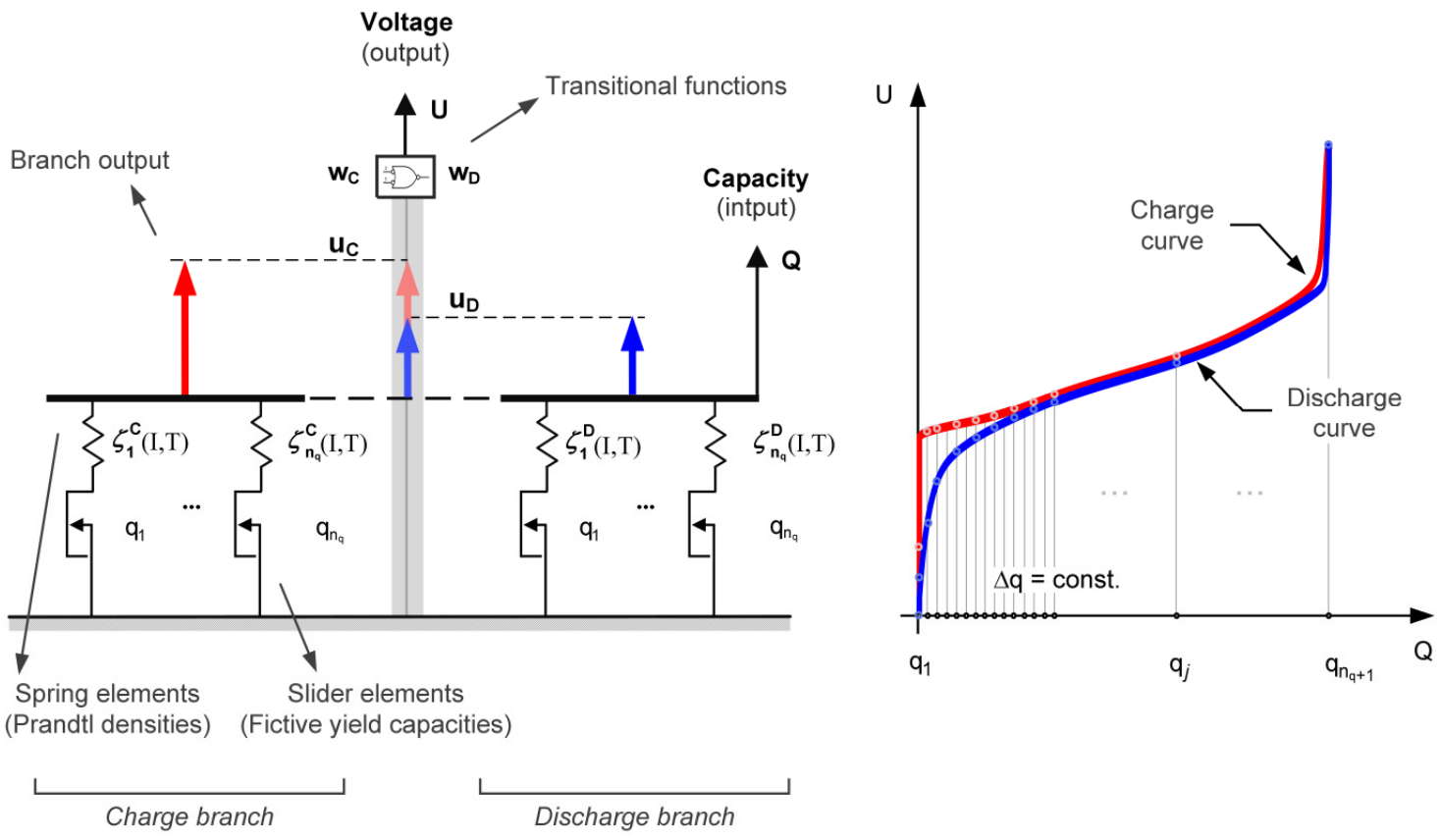

Fig. 1. The macro-scale phenomenological LIB model made of two independent branches of spring-slider segments of a Prandtl type. The model is controlled by the input capacity $Q$, calculated from the current history. Transitional charge function $w_{\mathrm{C}}$ and transitional discharge function $w_{\mathrm{D}}$ are needed to obtain the correct total voltage output $U . \Delta q$ denotes equidistant yield capacities $q_{j}$.

The original Prandtl operator ensures modelling of symmetric hysteresis loops. This is accomplished by comparing load, such as strain, with the previous load and play on each side [39]. If hysteresis loop is not symmetric it could be split into two branches, e.g. ascending and descending, with each branch being controlled by their own operator. This is achieved by comparing the current load, such as here employed capacity, with the previous load and play on one side only. In case of the LIBs, when the battery is being charged the capacity input is applied to the charge branch of the model with the charging stiffness of springs $\zeta_{j}^{C}(I, T)$ (Prandtl densities). On the contrary, when the battery is being discharged the capacity is applied to the discharge branch of the model with the discharging stiffness of 
springs $\zeta_{j}^{\mathrm{D}}(I, T)$. Fictive yield capacities $q_{j}$ for $j=1, \ldots, n_{\mathrm{Q}}+1$ are usually dispersed equidistantly with constant fictive yield capacity class width $\Delta q$ between minimum expected capacity and the maximum expected capacity as shown in Fig. 1. The Prandtl densities $\zeta_{j}^{C}(I, T)$ and $\zeta_{j}^{\mathrm{D}}(I, T)$ in the range $j=1, \ldots, n_{\mathrm{Q}}-1, k=1, \ldots, n_{\mathrm{I}}$ and $l=1, \ldots, n_{\mathrm{T}}$, are gained from the available $U-Q$ curves as given by Eq. 1. This way current and temperature charge and discharge curves are split into piecewise linear segments, each associated to the corresponding spring-slider segment of the model. As the procedure is identical for charge and discharge branch, $\mathrm{C}$ and $\mathrm{D}$, respectively, are for clarity omitted and replaced by the corresponding relay $\mathrm{M}$ giving the following relation:

$\zeta_{j}^{\mathrm{M}}\left(I_{k}, T_{l}\right)=\frac{1}{\Delta q}\left(U_{j+1}^{\mathrm{M}}\left(I_{k}, T_{l}\right)-2 U_{j}^{\mathrm{M}}\left(I_{k}, T_{l}\right)+U_{j-1}^{\mathrm{M}}\left(I_{k}, T_{l}\right)\right)$

for $\mathrm{M}=\mathrm{C}$ representing charge branch related parameters and $\mathrm{M}=\mathrm{D}$ representing discharge branch related parameters with $U_{0}^{\mathrm{M}}\left(I_{k}, T_{l}\right)=U_{1}^{\mathrm{M}}\left(I_{k}, T_{l}\right)=U_{\mathrm{MIN}}$, where $U_{\mathrm{MIN}}$ is the minimum voltage of the battery observed in experiments. The latter is needed to properly prepare the experimental data for each branch. $n_{\mathrm{Q}}$ represents the number of springs within the model, i.e. typically more than $100, n_{\mathrm{I}}$ represents the number of available current dependent curves and $n_{\mathrm{T}}$ represents the number of available temperature dependent curves. The same fictive yield capacities should be set for all available curves.

Each capacity value is calculated by numerical integration of the current in time for every instance $i$ in the time history for both charge and discharge branches independently by:

$Q_{i}=Q_{i-1}+\frac{\left(I_{i}-I_{i-1}\right)\left(t_{i}-t_{i-1}\right)}{2} ; i=1, \ldots, n$ 
where $Q_{0}=0$. It should be noted that minimum capacity of the battery $Q_{\mathrm{MIN}}$ observed during experiments needs to be subtracted from the capacity signal and then the corrected capacity joined by the information of current and temperature $Q_{i}^{*}=Q_{i}\left(I_{i}, T_{i}\right)-Q_{\mathrm{MIN}}$ in every instant of time $t_{i}$ is used to correctly run the capacity controlled play operator as given by Eq. 3 .

$$
\begin{aligned}
& q_{\zeta j, i}^{\mathrm{M}}=\max \left\{Q_{i}^{*}-q_{j}, \min \left\{Q_{i}^{*}, \frac{\zeta_{j}^{\mathrm{M}}\left(I_{i}, T_{i-1}\right)}{\zeta_{j}^{\mathrm{M}}\left(I_{i}, T_{i}\right)} q_{\zeta, i-1}^{\mathrm{M}}\right\}\right\} ; j=1, \ldots, n_{\mathrm{Q}} \\
& Q_{\zeta j, i}^{\mathrm{C}}=\max \left\{Q_{i}^{*}-q_{j}, \min \left\{Q_{i}^{*}, \frac{\zeta_{j}^{\mathrm{C}}\left(I_{i}, T_{i-1}\right)}{\zeta_{j}^{\mathrm{C}}\left(I_{i}, T_{i}\right)} Q_{\mathrm{MIN}}^{*}\right\}\right\} ; j=1, \ldots, n_{\mathrm{Q}} \\
& Q_{\zeta j, i}^{\mathrm{D}}=\max \left\{Q_{i}^{*}-q_{j}, \min \left\{Q_{i}^{*}, \frac{\zeta_{j}^{\mathrm{D}}\left(I_{i}, T_{i-1}\right)}{\zeta_{j}^{\mathrm{D}}\left(I_{i}, T_{i}\right)} Q_{\mathrm{MAX}}^{*}\right\}\right\} ; j=1, \ldots, n_{\mathrm{Q}}
\end{aligned}
$$

where $Q_{\mathrm{MIN}}^{*}=0$ and $Q_{\mathrm{MAX}}^{*}$ is the highest experiment capacity $Q_{\mathrm{MAX}}$ reduced for the minimum capacity of the battery $Q_{\mathrm{MIN}}$, resulting in $Q_{\mathrm{MAX}}^{*}=Q_{\mathrm{MAX}}-Q_{\mathrm{MIN}}$. The second and the third relations presented in Eq. 3 differ from the first by comparing the current load with the boundary curves and the play rather than with the previous load and the play.

Back stresses $q_{\zeta j, i}^{\mathrm{C}}$ and $q_{\zeta j, i}^{\mathrm{D}}$ are multiplied by corresponding Prandtl densities $\zeta_{j}^{\mathrm{C}}\left(T_{l}\right)$ and $\zeta_{j}^{\mathrm{D}}\left(T_{l}\right)$, respectively, give possible battery voltages in every branch of the model in that instant of time

$$
\begin{aligned}
& u_{\mathrm{M} i}=\sum_{j=1}^{n_{\mathrm{Q}}} \zeta_{j}^{\mathrm{M}}\left(I_{i}, T_{i}\right) q_{\zeta, i}^{\mathrm{M}}, \\
& U_{\mathrm{M} i}=\sum_{j=1}^{n_{\mathrm{Q}}} \zeta_{j}^{\mathrm{M}}\left(I_{i}, T_{i}\right) Q_{\zeta j, i}^{\mathrm{M}},
\end{aligned}
$$

where, if $\mathrm{M}$ is replaced by $\mathrm{C}$ or $\mathrm{D}$, the corresponding $u_{\mathrm{C} i}, u_{\mathrm{D} i}, U_{\mathrm{C} i}$ and $U_{\mathrm{D} i}$ represent transitional charge, transitional discharge, boundary charge and boundary discharge voltages, respectively. Transitional charge and transitional discharge voltages are needed for 
simulation of a smooth behaviour between the charge and the discharge branches as observed in experiments. The transition is controlled by a transitional charge function $w_{\mathrm{C}}\left(Q_{i}\right)$ and a transitional discharge function $w_{\mathrm{D}}\left(Q_{i}\right)$ as schematically depicted in Fig. 1. Acquiring $w_{\mathrm{C}}\left(Q_{i}\right)$ and $w_{\mathrm{D}}\left(Q_{i}\right)$ that yield a correct $U-Q$ output is not a straightforward task, since the shape of each of the nested loop varies with respect to the size of the loop and its position (mean capacity) within the extremities of the boundary loop. It is assumed that transitional functions are not limited to any mathematical function as long as they optimally perform the transition. Here, an exponential type function was used for charge transition and for the discharge transition e.g. $w_{\mathrm{M}}\left(\mathrm{Q}_{i}\right)=e^{-\mathrm{a}_{\mathrm{M}} x}$ as it provided the most visually satisfying transitions between charge and discharge branch as compared to observed experimental behaviour. The corresponding parameters $\mathrm{a}_{\mathrm{C}}$ and $\mathrm{a}_{\mathrm{D}}$ can be set manually or by an optimisation procedure adjusted to material data numerically. The simulated output voltage $U_{i}$ can then be obtained as follows

$U_{i}=u_{\mathrm{D} i}+U_{\mathrm{MIN}}$

where $U_{\text {MIN }}$ is the minimum voltage of the battery observed in experiments. At this point $U_{\text {MIN }}$ is added because the Prandtl operator approach considers only the relative change of voltage regarding the minimum value $U_{\text {MIN }}$.

Calculation of $u_{\mathrm{D} i}$ is more demanding due to the hysteresis effect and cycle nesting behaviour. It is always difficult to present a complex computational algorithm descriptively, therefore, a pseudo code of the procedure as depicted in Fig. 2 is given. In line 1, of the code, variables $\Delta U_{\mathrm{C}}$ and $\Delta U_{\mathrm{D}}$ denote the charge voltage shift and the discharge voltage shift, respectively. In line 4, Recalc variable is used to check whether current or temperature has changed with respect to the previous state. $q_{\mathrm{MAXC}}$ in line 6 represents the reversal point 
of the current and temperature dependent experimental $U-Q$ curve that corresponds to the $i-$ th input of $I$ and $T$. If necessary, the number of required experimental $U-Q$ curves at different levels of $I$ and $T$ can be reduced by interpolation or extrapolation of available data as explained in details in the following section. In order to correctly match the $i-$ th input of $I$ and $T$ with the corresponding $U-Q$ curve, $I$ and $T$ need to be properly rounded-up. It should be noted that with a proper data preparation the difference between the rounded values and the input values can be insignificant. The variable input temperature history is accounted for automatically by properly modifying the stiffness of the spring elements. The modification is controlled by the temperature correction factor $m_{\mathrm{M}}$, calculated in line 18 . The rest of the code is dedicated to work out the proper voltage transition between the charge and the discharge branch as well as to obtain the corresponding voltage output.

The complete numerical procedure following the pseudo code was coded in the freeware software environment $\mathrm{R}$, however any other programming environment and language can be used. 


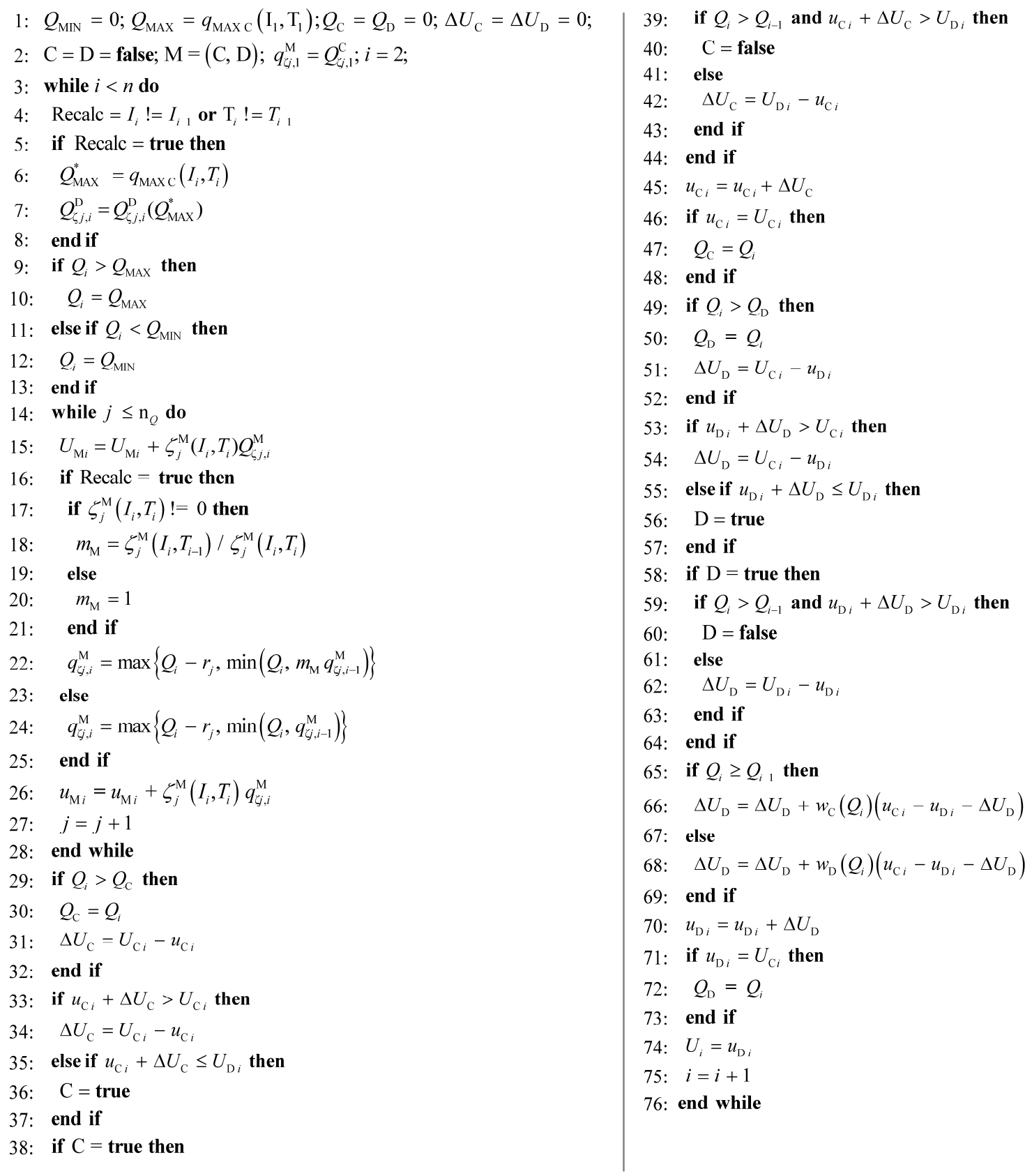

Fig. 2. The pseudo code of the battery model calculation procedure.

\subsection{Calibration}

Batteries can have different compositions and chemistries, which directly affect the $U-Q$ response. Hence, battery model calibration or model parameter calibration e.g. Prandtl densities given by Eq. 1, needs to be performed independently for the specific type of battery 
considered in simulations. It should be noted that the presented model works only for monotonically increasing and monotonically decreasing curves, namely the boundary charge and the boundary discharge curve, respectively. They can be extracted from representative cycles obtained experimentally by performing fully reversed cyclic tests during which the battery is charged and discharged sequentially between empty (100\% depth of discharge) and a full capacity. It is expected that tests are carried out for currents and temperatures within the expected actual load range, e.g. between $5 \%$ and $95 \%$ depth of discharge. If number of tests is to be kept at minimum, at least representative curves for both, the upper and the lower charge and discharge current and temperature extremities should be provided. To this end, interpolation could be used to determine the parameters at intermediate currents and temperatures, i.e. linear or piecewise cubic Hermite interpolation.

After Prandtl densities for the $U-Q$ curves are generated, they are interpolated between both, the lowest and the highest currents and the lowest and the highest temperatures, according to the number of selected discrete divisions. In order to consider all available experimental data, intermediate experimental charge-discharge curves are also added to interpolated curves. If, for example, three test temperatures existed at $10^{\circ} \mathrm{C}, 15^{\circ} \mathrm{C}$ and $40^{\circ} \mathrm{C}$ and only ten temperature divisions were chosen by the user, the test at $15{ }^{\circ} \mathrm{C}$ would not have been possible to simulate as that temperature would not have been one of the interpolated temperatures. As intermediate experimental curves are added to the interpolated temperatures, experimental conditions can always be exactly simulated.

\subsection{Load history preparation}

Load history $L$ enters the procedure for modelling the $U-Q$ response and should be prepared prior to calculation. The history consists of subsequent time instants, each holding information on loading and environmental conditions of the battery as shown in Fig. 3, 
$L=L\left(t_{i}\right)=L\left(I_{i}, T_{i}\right) ; \quad i=1, \ldots, n_{\mathrm{L}}$

where $I_{i}=I\left(t_{i}\right)$ and $T_{i}=T\left(t_{i}\right)$ represent current and temperature histories at discrete time instants, respectively.

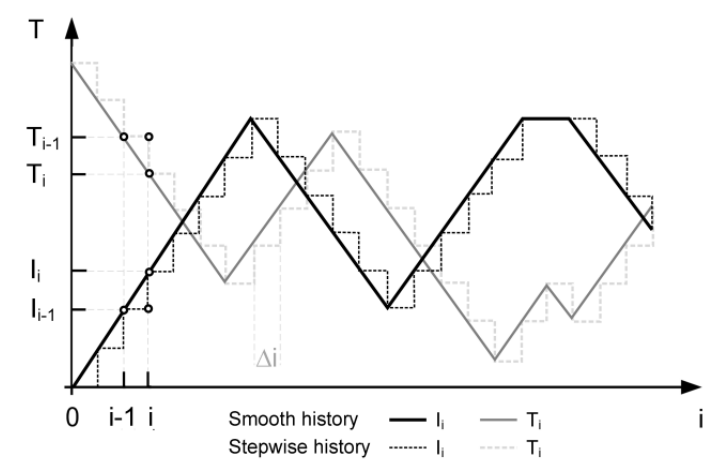

Fig. 3. The load history represents current and temperature instants during the charge/discharge process of the battery.

As the modelling of the $U-Q$ response is time-dependent, sufficiently small increments have to be considered during experiments in order to minimise the discretisation error in later simulations. If time increments of the input history are not as required by the approach, the following procedure can be used to properly prepare the experimental data. In order to gain the information of the load history at both small and equal time intervals, the maximum number of data points between two successive time instants is first searched for as:

$n=\max \left(\left\lceil\frac{\left|I_{i}-I_{i-1}\right|}{\Delta I} \mid,\left\lceil\frac{\left|T_{i}-T_{i-1}\right|}{\Delta T} \mid\right) ; \quad i=2, \ldots, n_{\mathrm{L}}\right.\right.$

where $\Delta I$ and $\Delta T$ stand for predetermined history discretisation steps and $\lceil x\rceil$ represents the ceiling function, defined by $\lceil x\rceil=\min \{n \in \mathbb{Z} \mid n \geq x\}$. The histories are then complemented by the missing values at new time instants as

$I_{i, j}=I_{i-1}+j \Delta I_{i} ; \quad T_{i, j}=T_{i-1}+j \Delta T_{i} ; i=2, \ldots, n_{\mathrm{L}} ; j=1, \ldots, n$

where 
$\Delta I_{i}=\frac{I_{i}-I_{i-1}}{n} ; \Delta T_{i}=\frac{T_{i}-T_{i-1}}{n} ; i=2, \ldots, n_{\mathrm{L}}$

Eq. 8 can be rewritten into

$I_{i}=I_{j, k} ; T_{i}=T_{j, k} ; i=1, \ldots, n_{\mathrm{L}} \cdot n ; j=1, \ldots, n_{\mathrm{L}} ; k=1, \ldots, n$

where the time dependence is described by one index only. Next, the values of the current and the temperature histories $I_{i}$ and $T_{i}$ from Eq. 10 are assigned the closest available values $I$ and $T$ from the discretised stabilised $U-Q$ curves,

$I_{i}=\left\{I[j] \mid\left(I[j]<I_{i}<I[j+1]\right) ; j=1, \ldots, n_{I}+1\right\}$

$T_{i}=\left\{T[j] \mid\left(T[j]<T_{i}<T[j+1]\right) ; j=1, \ldots, n_{T}+1\right\}$

As the $U-Q$ behaviour is modelled with discretised current and temperature dependency a stepwise resulting cyclic capacity $Q\left(t_{i}\right)$ is usually observed. However, with smaller discretisation steps the result becomes smoother.

This ensures a very fast $U-Q$ response calculation as the values of the Prandtl densities $\zeta_{j}^{\mathrm{C}}(I, T)$ and $\zeta_{j}^{\mathrm{D}}(I, T)$ for the discretised currents and temperatures can be easily invoked by knowing the corresponding indices in the matrix of pre-calculated Prandtl densities only. The determination of the current and temperature dependent Prandtl densities and their matrix notation is given by Eq. 1 .

In the next section, two examples serving as practical demonstration and validation of the developed battery model are presented. Details of the preliminary input load history data preparation and the model calibration are provided first. In Section 4.1 and 4.2, two additional examples with both the calibration (sea Section 3.2) and the input load history simulation are presented for the conventional first-order Thevenin ECM topology.

\section{Experimental}




\subsection{Model calibration}

The initial calibration of the Prandtl battery model has been made using a set of experimental data for a $\mathrm{LiNiMnCoO}_{2}$ (NMC) type of battery cell - a chemistry with high specific energy storage capabilities primarily used in power-demanding applications like power tools, EVs and other electric powertrains. Cell specimens had a nominal capacity of $20 \mathrm{Ah}$ and rated voltage range between $3.0 \mathrm{~V}$ and $4.15 \mathrm{~V}$. More details on the cell can be found elsewhere $[44,45]$.

Tests were carried out at predefined charge and discharge currents and two distinct temperatures, e.g. $25^{\circ} \mathrm{C}$ and $45^{\circ} \mathrm{C}$. Various discharge rates were available only for $25{ }^{\circ} \mathrm{C}$ and only one charge and one discharge curve were available at $45^{\circ} \mathrm{C}$. The battery was cycled between $5 \%$ and $95 \%$ depth of discharge during the constant amplitude tests therefore the fictive yield capacity values could have only been determined within this range. As the battery did not exceed these boundaries during the validation examples, this assumption can be justified. However, if constant amplitude tests were available between 0 $\%$ and $100 \%$ depth of discharge, then the fictive yield capacity values could cover the actual capacity of the battery.

The intermediate curves for non-measured currents were interpolated. As the generation of Prandtl densities requires that the same numbers of charge and discharge curves are provided for every test temperature, extrapolation to lower current rates was also necessary. For both, charge and discharge curves at $45{ }^{\circ} \mathrm{C}$, extrapolation to $0 \mathrm{C}$ rate has been performed. The procedure is as follows. For the chosen representative curve at each temperature, a middle voltage $U_{0 i}$ is calculated as follows

$U_{0 i}=\frac{U_{\mathrm{C} i}+U_{\mathrm{D} i}}{2}$

for every fictive yield capacity $q_{j}$ and $j=1, \ldots, n_{\mathrm{Q}}$ as shown in Fig. 4 . This value is then considered as the charge curve for $0 \mathrm{C}$ charge rate and discharge curve for $0 \mathrm{C}$ discharge 18 
rate. It could also be determined in another way, e.g. for $25^{\circ} \mathrm{C}$ by looking at the trend of discharge curves for different rates. In the present procedure, the above-mentioned calculation of this curve has given satisfactory results.

The described curve preparation improved modelling of hysteresis loops without the occurrence of high peaks by a swap from charge to discharge mode or vice versa. These could occur without inclusion of the $0 \mathrm{C}$ curves as the first available curve was that for $0.5 \mathrm{C}$ charge and $1 \mathrm{C}$ discharge rate although the rates in the load cycle could be well below that value. Only experimental curves without extrapolation to higher charge and discharge rates have been used for the $U-Q$ response simulation, although experimental curves for higher rates could be included if they were available.

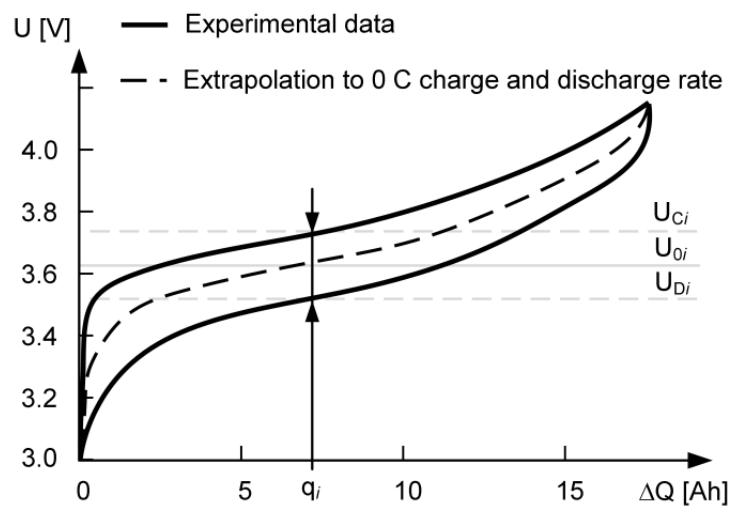

Fig. 4. Determination of the extrapolated charge curve for $25{ }^{\circ} \mathrm{C}$ to $0 \mathrm{C}$ rate and extrapolated discharge curve to $0 \mathrm{C}$ rate (denoted by dashed line).

The employed current and temperature curves are presented in Fig. 5, where solid pointing arrows indicate experimental data whilst dashed pointing arrows indicate extrapolated data. Red solid lines represent interpolated curves. For the graphic representation, 20 divisions for the current and 10 divisions for the temperature are depicted, whereas for the satisfying results of simulation, 128 current divisions and 20 temperature divisions have been utilised. It should be pointed out that the charge and the discharge curves are presented in the voltagecapacity dependency as this form of data is required for the developed model calibration 
procedure. However, knowing the corresponding charge or discharge currents the curves can easily be converted to a more conventional presentation of the voltage-time dependency.

Optimal values of the exponents $\mathrm{a}_{\mathrm{C}}$ and $\mathrm{a}_{\mathrm{D}}$ to define the transitional charge and discharge functions $w_{\mathrm{C}}\left(Q_{i}\right)$ and $w_{\mathrm{D}}\left(Q_{i}\right)$, respectively, were set with respect to the experimental data. Here, $\mathrm{a}_{\mathrm{C}}=3.5$ and $\mathrm{a}_{\mathrm{D}}=0$ were used.
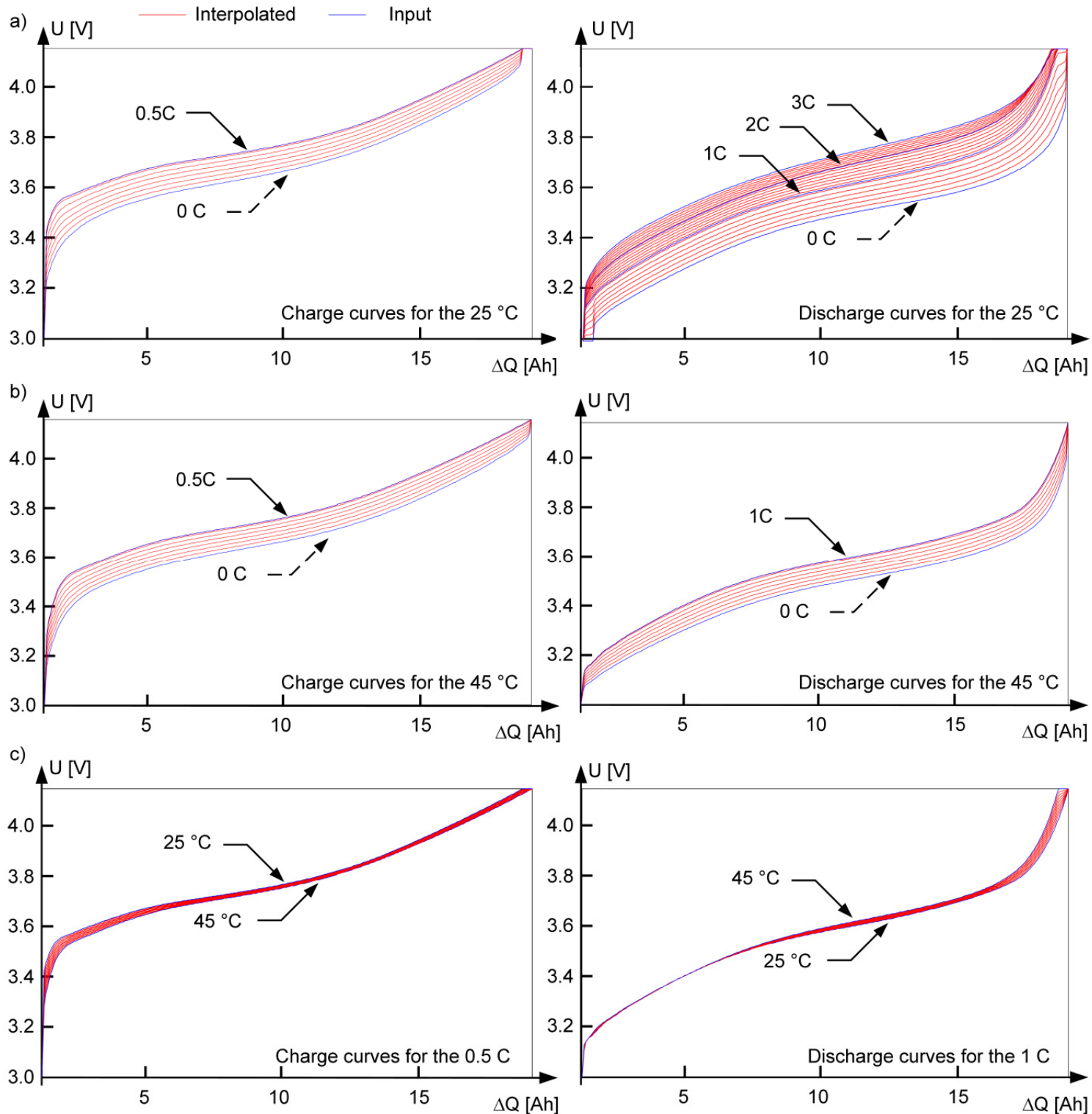

Fig. 5. Current and temperature dependent input $U-Q$ curves where top blue lines represent input curves, red lines represent interpolated curves and dashed arrows denote 
extrapolated curves; a) current dependent $U-Q$ charge (left) and discharge (right) curves for the $\left.25^{\circ} \mathrm{C}, \mathrm{b}\right)$ current dependent $U-Q$ charge (left) and discharge (right) curves for the $45^{\circ} \mathrm{C}, \mathrm{c}$ ) temperature dependent $U-Q$ charge (left) and discharge (right) curves for the $0.5 \mathrm{C}$ charge and the $1 \mathrm{C}$ discharge current.

The developed approach has been validated on three examples. Results of comparison between both the measured battery response and the simulated response are presented in next sections.

\subsection{Equivalent circuit model calibration}

In order to improve the validation of the developed model, a comparison with the established resistor-capacitor (RC) Thevenin equivalent circuit model [46] was performed. The first-order RC model is graphically presented in Fig. 6. As shown in the figure, the model is made of an ideal current source $\mathrm{I}_{\mathrm{IN}}$. Ohmic resistors $R_{0}$ and $R_{1}$ represent electrolyte resistance and polarisation resistance, respectively [46], capacitor $C_{1}$ stands for polarisation capacitance and $U_{\mathrm{OC}}$ represents open circuit voltage [46]. Voltage $U_{\mathrm{OUT}}$ is measured in parallel with the battery model. All parameters are considered as state-of-charge (SOC) dependent [46]. This is measured by the Coulomb counting technique whereas current and terminal voltage are measured directly by ideal sensors without internal resistance.

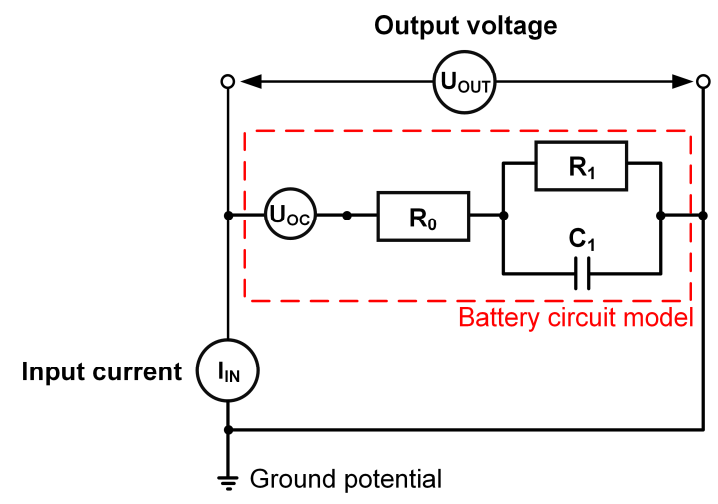

Fig. 6. Current controlled first-order resistor-capacitor or Thevenin equivalent circuit model. 
Adding additional RC pairs and other electric components to the model (second or higherorder models) can considerably affect the model complexity, calibration procedure and improve modelling capabilities [47]. The RC model parameters, e.g. $R_{0}, R_{1}, C_{1}$ and $U_{\mathrm{OC}}$, are usually calibrated against experimental data relative to SOC, current, temperature and battery freshness (state of health) by optimisation algorithms or using advanced parameter estimation methods such as genetic algorithms for the complex models comprising ordinary differential equations [48]. As the ECM parameter calibration is essentially an optimisation problem, finding the optimal solution is usually not a straightforward task. There are several important concerns that influence the calibration outcome, such as issues with the availability and the type of experimental data, properties of selected optimisation algorithm or even the method for estimation of initial values. Furthermore, issues with local extrema, evaluation and implementation of statistical differences between the analysed specimens and a considerable computational effort represent additional challenges at the calibration stage of the model [49].

The battery chemistry under investigation has already been thoroughly investigated by e.g. Nikolian et al. [45, 49]. In addition, such material characterisation tests were used to calibrate the parameters of the employed enhanced second-order RC battery model that consider the normal, advanced and performance properties of the battery chemistry. The model response was successfully tested (typically error below $+/-2 \%$ ) on highly dynamic load profile as can be found in EV applications.

As the input data for the battery chemistry used in this paper (see Section 3.1) was limited as compared to the above mentioned investigations, the RC model parameter calibration was carried out on this limited set of experiments. Then, the results of the simulations have been compared to the results using the Prandtl model. The employed model was the isothermal first-order RC model as presented in Fig. 6 . The RC circuitry was programmed in the Matlab Simulink environment. Model parameters were estimated separately for each available charge and discharge curve at $45^{\circ} \mathrm{C}$ in the Matlab by the Parameter Estimation program. 
The calibration input curves for the input $-20 \mathrm{~A},-1 \mathrm{~A}, 1 \mathrm{~A}$ and $10 \mathrm{~A}$ current are presented in Fig. 5b and Fig. 5c. It should be stressed that the same curves were used as for the calibration of the developed Prandtl battery model presented in the Section 2.1, hence both models were exposed to the same calibration inputs. Optimal parameters were then imported to the current dependent $\mathrm{RC}$ model in a form of lookup tables, essentially representing the current and SOC dependent characteristics of individual electrical elements. A linear interpolation was assumed for the parameter values between the input currents. The estimated parameter values of $R_{0}, R_{1}, C_{1}$ and $U_{\mathrm{OC}}$ across the complete SOC levels and all input currents are presented in Fig. 7.

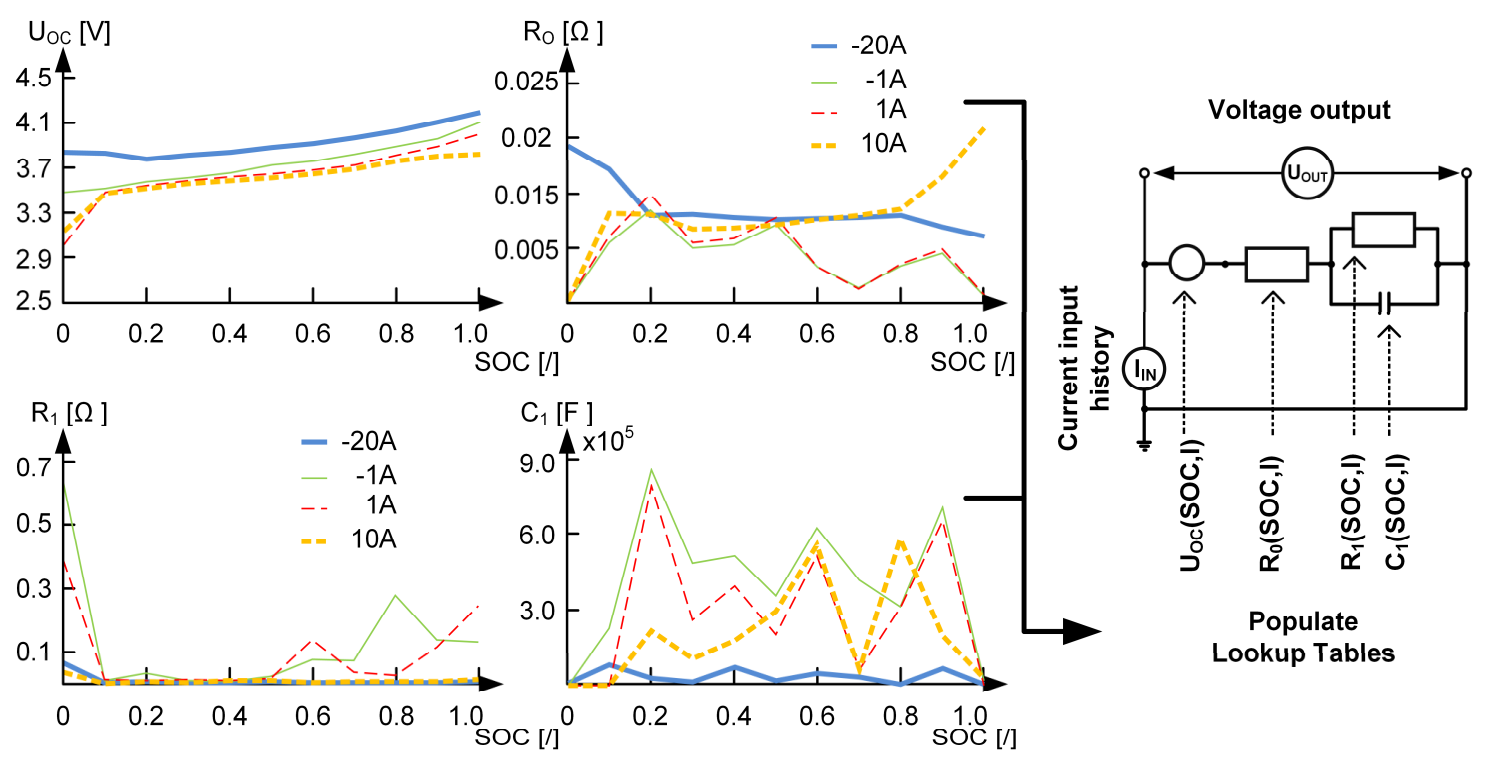

Fig. 7. Estimated current dependent parameters of the RC model.

\section{$4 \quad$ Results}

\subsection{Simulation for nested profile}

The first two examples demonstrate the simulated battery response for the assumed nested (incremental) capacity controlled load history at two distinct constant temperatures. The capacity history integrated from the input current history at $25^{\circ} \mathrm{C}$ is depicted in Fig. 8 a, whilst the integrated capacity history at $45^{\circ} \mathrm{C}$ is depicted in Fig. $8 \mathrm{c}$. 


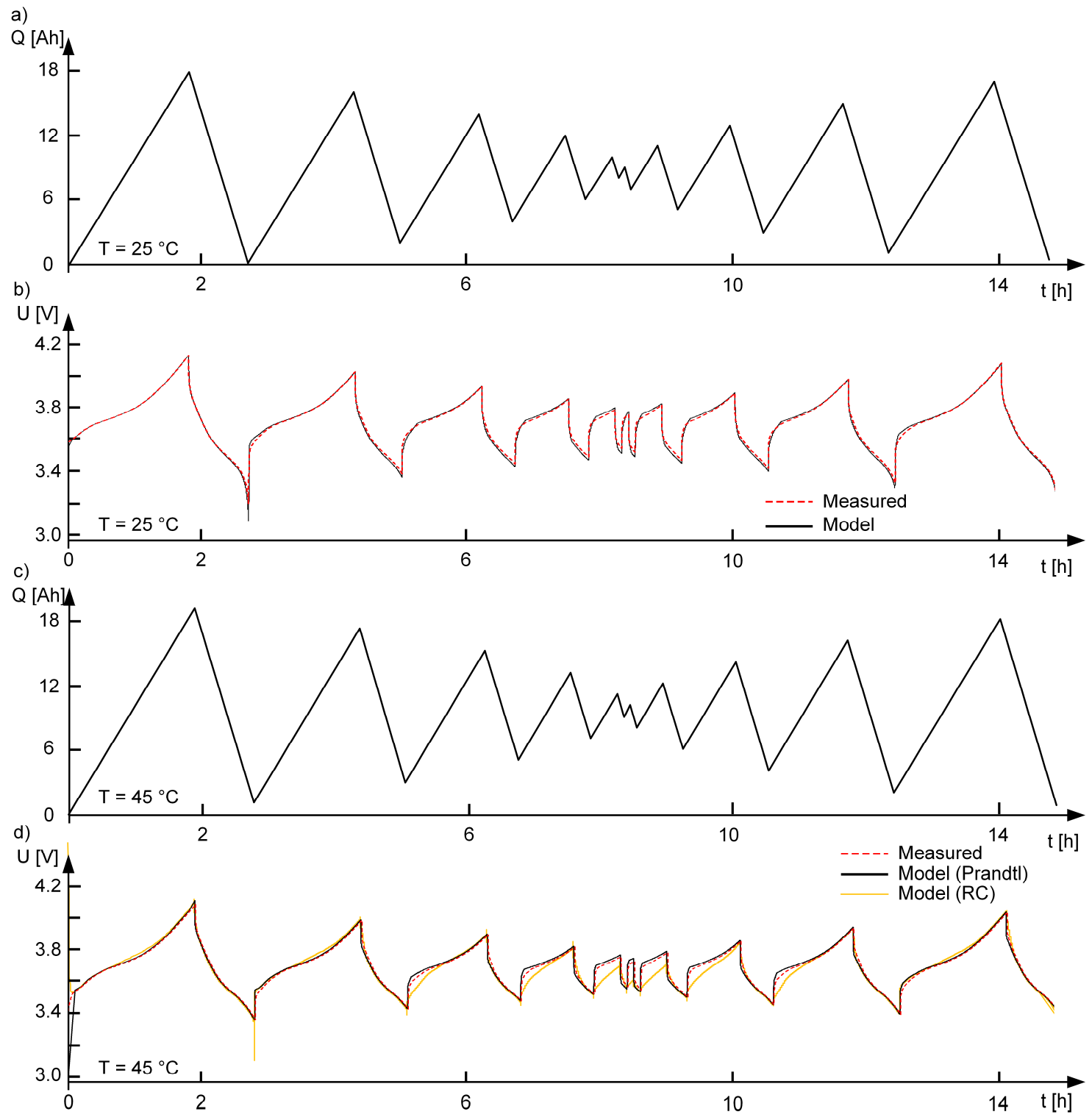

Fig. 8. Results of the incremental test (a) input capacity load history at $25{ }^{\circ} \mathrm{C}$ (b) measured (red dashed line) and simulated (black solid line) voltage battery responses at $25^{\circ} \mathrm{C}$ (c) input capacity load history at $45^{\circ} \mathrm{C}$ (d) measured (red dashed line) and simulated (black solid line) voltage battery responses at $45^{\circ} \mathrm{C}$.

The simulated battery response is compared against the measured voltage response. Results for both load history at $25{ }^{\circ} \mathrm{C}$ and at $45{ }^{\circ} \mathrm{C}$ are presented in Fig. $8 \mathrm{~b}$ and Fig. $8 \mathrm{~d}$, respectively. The simulated response of the first-order RC model at $45^{\circ} \mathrm{C}$ is presented in Fig. $8 d$.

\subsection{Simulation for EV application profile}


The second example is used to demonstrate the performance of the model on the arbitrary load history, to which the battery could be exposed if used i.e. in an EV application [50]. The world-wide harmonized light vehicles test cycle (WLTC) [51] containing typical driving data collected around the world was used to design the input current history. The repeated load sequence, depicted in Fig. 9, contains five repetitions of the WLTC profile, followed by a charge period to $90 \%$ state of charge at $0.5 \mathrm{C}$ and a rest period of 20 minutes. A complete repetition of the load history is simulated, as highlighted. Initially, the battery has been charged for $1.830 \mathrm{~h}$ with $10 \mathrm{~A}$ to reach a starting charged stage. Temperature was kept constant during the entire procedure at $45^{\circ} \mathrm{C}$.

Experimental $Q_{\mathrm{EXP}}$ and integrated capacity values $Q_{\mathrm{INT}}$ are shown in Fig. 9b with solid line and red circles, respectively. The capacity $Q$ is calculated first as given by Eq. 2 . It is important for the outcome of the simulation that the input $Q_{\mathrm{INT}}$ history reflects $Q_{\mathrm{EXP}}$ load history as much as possible. Here, the difference between the histories is negligible (see Fig. 9b). $Q_{\mathrm{INT}}$ was then used to simulate the WLTC load cycles.
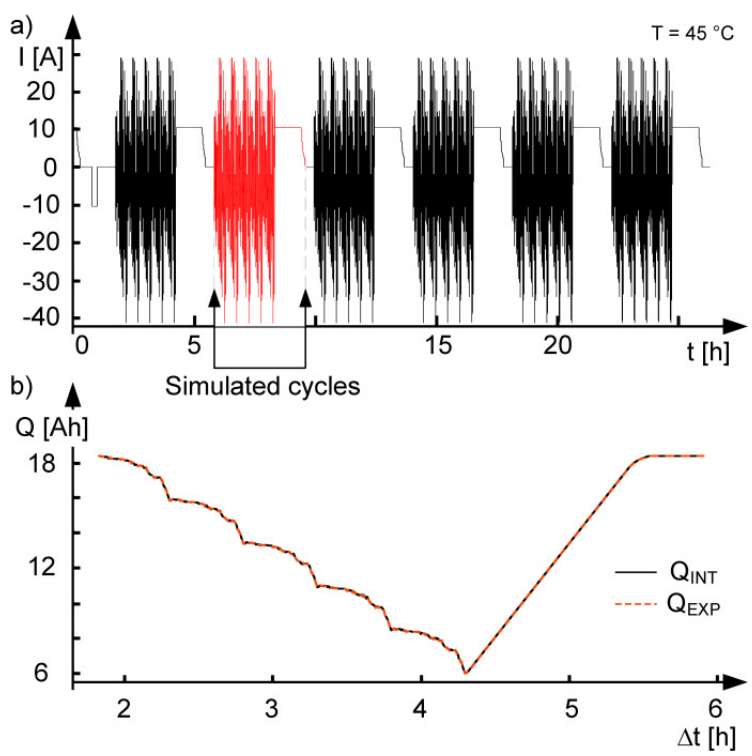

Fig. 9. WLTC input (a) the complete sequence of six load cycles and the analysed current load cycle between 5.928 hour and 9.926 hour, (b) experimental and integrated capacities for 
the load cycle.

Measured and simulated voltage responses are shown in Fig. 10, where red dashed line represents measured values, solid black and yellow line represent simulated values for Prandtl model and RC model, respectively. The measured signal of voltage starts after charging to $90 \%$ state of charge.

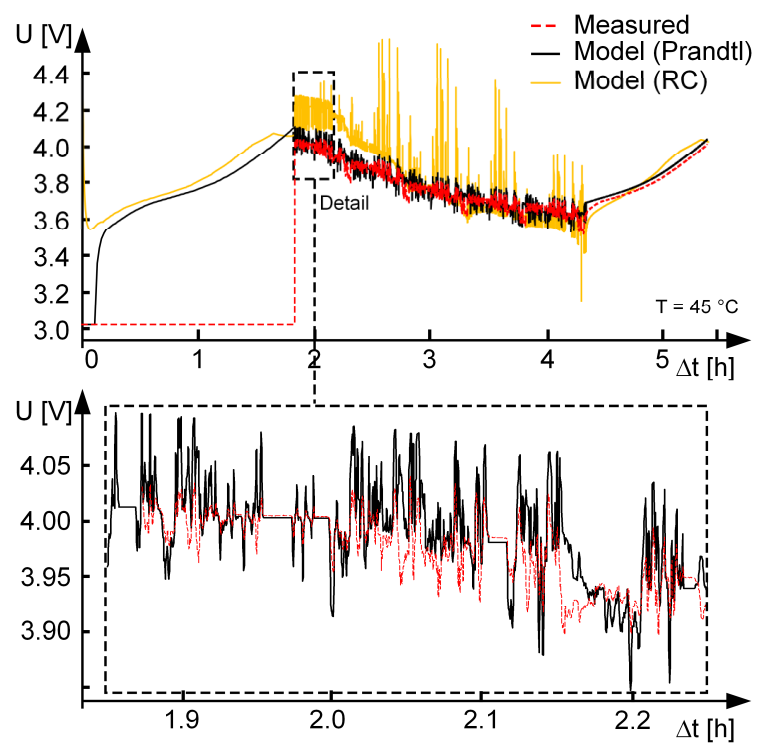

Fig. 10. Measured (red dashed line) and simulated voltage responses (black solid line for the Prandtl model and yellow solid line for the RC model) with a detailed view (measured and Prandtl model).

It can be noticed from Fig. 9 that the calculated and the measured capacities coincide on the whole time range, whereas the simulated and measured voltages depicted in Fig. 10 show discrepancies.

\section{Discussion}

Results presented in the previous section show that the Prandtl battery model can be applied to simulate the cyclic behaviour of LIBs. Three examples, namely the nested profile at two distinct temperatures e.g. $25^{\circ} \mathrm{C}$ and $45^{\circ} \mathrm{C}$ and the WLTC profile at $45^{\circ} \mathrm{C}$, are used to show the capabilities of the model. Good agreement is achieved between the $U-Q$ simulation at constant temperature and the measured path. It should be noted that the outcome is greatly influenced by the material data and model calibration, thus conclusions should relate only to 
these specific input data. In Fig. 8a-8d minor deviations of the simulated response were therefore expected, mainly due to the assumptions regarding the model calibration. Namely, the nested profiles have been carried out on a fresh cell as opposed to the behaviour it was calibrated for. It can also be observed that the $\mathrm{RC}$ model is able to follow the measured signal for the first few cycles, however when the shape of the inner cycles change considerably, the RC model with parameters fitted to the boundary curve starts departing from the measured path.

In order to improve battery behaviour modelling extrapolation to $0 \mathrm{C}$ rate for both charge and discharge curves has been performed. This improved modelling of hysteresis loops without the occurrence of high peaks by a swap from charge to discharge mode or vice versa. These could occur before as the first available curves were that for $0.5 \mathrm{C}$ charge and $1 \mathrm{C}$ discharge rates although the rates in the load cycle could be well below that value.

The comparison of the three cell voltage signals presented in Fig. 10 reveals that the simulated battery response using the Prandtl model correctly follows the input history (reversal points); however, it tends to have an amplitude deviation as compared to the measured signal. This effect might be attributed to time dependent physical properties of the battery material (transient response), which are currently not yet included in the model. RC response shows more deviation from the measured signal as compared to the developed Prandtl model. Although the model parameters were successfully fitted to the input curves it seems that the RC model of the form depicted in Fig. 6 experiences higher fluctuations in the simulated voltage when considering the WLTC profile. It could be argued that the response of the RC model can be enhanced significantly [45], but to achieve that, the model requires an electrical circuit of a more complex form with a broader spectrum of material parameters. Furthermore, also a broader range of experiments is required to utilise such an RC model, e.g. impulse charge and discharge curves for different currents, temperatures and battery's state of health $[45,49]$. A list of main advantages of the Prandtl battery model as compared to $\mathrm{RC}$ models can therefore be presented as follows: 
- The number of required material parameters and the corresponding material tests is minimised. A procedure to properly prepare both the available and the missing experimental battery data was developed.

- Variable current and temperature input histories can be used to obtain the temperature dependent voltage response.

- Complex variable loading histories resulting in nested hysteresis loops are resolved automatically by the developed model consisted by two independent branches of springslider segments of a Prandtl type. One branch is used to simulate the charge and the other one is used to simulate the discharge process. Hence, two different sets of charge and discharge curves can be used in the simulation (in common with RC models).

- Calculation algorithm of the material data preparation and the battery model was implemented in a freeware code in $\mathrm{R}$. The pseudo code of the procedure is provided in order to support the implementation of the calculation algorithm in $\mathrm{R}$ or any other program language.

- Computation time is minimised due to the material data preparation procedure which is carried out prior to battery response simulation.

- No numerical optimisation of the model parameters and estimation of initial values is required which prevents the difficulties with local extrema, solution convergence and multiple solutions.

- The model in the presented form can also be used for other chemistries as long as charge and discharge curves are monotonically increasing and decreasing, respectively.

It should be noted that all material and model related data such as Prandl densities, yield planes, current and temperature curve interpolation etc. are prepared beforehand, hence a little more computational effort is needed at the beginning of the analysis. It could be argued that many parameters are fitted in the approach presented here; however, among other 
differences to other approaches, like equivalent circuit models, is that the required material data and the corresponding computational effort is kept very low.

In addition, it is assumed that electric properties and internal structure as well as all chemical reactions within the battery can be represented by experimental response curves thus the approach could be classified as a macro-scale approach. This essentially means that it is not able to address the effect of a specific mechanism within the battery; instead, response of all underlying mechanisms combined is addressed as one. Furthermore, it is assumed that the measured values of current and temperature represent the real-time battery behaviour. However, if there exists a time delay of the measuring equipment and the responding time of the measuring equipment is known than this could also be considered in the simulation.

The paper addresses the challenges of the complex battery behaviour modelling, which is only the first task of the on-going research of the thermo-mechanical fatigue modelling for rechargeable batteries. Although the presented results are encouraging, further work should be carried out to improve both the model and the calibration procedure.

\section{Conclusions}

This paper presents a novel approach for simulation of temperature dependent cyclic battery behaviour. A new current controlled macro-scale phenomenological model based on the mechanical-electrical analogies and mechanistic concepts of the spring-slider Prandtl operator was developed. The model can be fitted to many charge and discharge curve types as long as they are monotonically increasing and decreasing. Therefore, the developed model can be used for continuous simulation of voltage response for both arbitrary current and arbitrary temperature load history of a LIB as well as other types of batteries, such as LiPo, Li-Fe etc. In that sense the presented approach and the model could be applied in the current form, and only material data assessment would require adaptation. Due to the model design the input data is minimised thus the required testing is considerably reduced. The approach was validated on several loading histories for a NMC type battery cell, including the 
world-wide harmonized light vehicles test cycle in the simulation for EV application. Results of simulations were successfully compared against the actual battery response.

\section{Acknowledgements}

This research has been made possible, thanks to the research project "BATTLE" and was funded by the Flemish Agency for Innovation and Entrepreneurship (Nr. IWT130019). Further, we acknowledge Flanders Make for the support to our research team. This paper is also a part of research work within program (Nr. P2-0182) entitled Development evaluation financed by the Slovenian Research Agency.

\section{References}

1. M. Lang, M. S. D. Darma, K. Kleiner, L. Riekehr, L. Mereacre, M. Á. Pérez, V. Liebau, H. Ehrenberg, Post mortem analysis of fatigue mechanisms in LiNi0.8Co0.15Al0.05O2 LiNi0.5Co0.2Mn0.3O2 - LiMn2O4/graphite lithium ion batteries, Journal of Power Sources, 326 (2016). http://dx.doi.org/10.1016/j.jpowsour.2016.07.010.

2. E. Sarasketa-Zabala, I. Gandiaga, E. Martinez-Laserna, L.M. Rodriguez-Martinez, I. Villarreal, Cycle ageing analysis of a LiFePO4/graphite cell with dynamic model validations: Towards realistic lifetime predictions, Journal of Power Sources, 275 (2015). http://dx.doi.org/10.1016/j.jpowsour.2014.10.153.

3. R. Zhao, J. Liu, J. Gu, A comprehensive study on Li-ion battery nail penetrations and the possible solutions, Energy, 123 (2017). https://doi.org/10.1016/j.energy.2017.02.017.

4. A. Jaiswal, S. C. Chalasani, The role of carbon in the negative plate of the lead-acid battery, Journal of Energy Storage, 1 (2015). http://dx.doi.org/10.1016/j.est.2015.05.002.

5. F. Moser, F. Fourgeot, R. Rouget, O. Crosnier, T. Brousse, In situ X-ray diffraction investigation of zinc based electrode in $\mathrm{Ni}-\mathrm{Zn}$ secondary batteries, Electrochimica Acta, 109 (2013). http://dx.doi.org/10.1016/j.electacta.2013.07.023. 
6. C. Hazotte, N. Leclerc, E. Meux, F. Lapicque, Direct recovery of cadmium and nickel from $\mathrm{Ni}-\mathrm{Cd}$ spent batteries by electroassisted leaching and electrodeposition in a single-cell process, Hydrometallurgy, 162 (2016). http://dx.doi.org/10.1016/j.hydromet.2016.02.019.

7. A. Mukhopadhyay, B. W. Sheldon, Deformation and stress in electrode materials for Li-ion $\begin{array}{lllll}\text { batteries, } & \text { Progress } & \text { (2014). }\end{array}$ http://dx.doi.org/10.1016/j.pmatsci.2014.02.001.

8. S. Jung, D. Kang, Multi-dimensional modeling of large-scale lithium-ion batteries, Journal of Power Sources, 248 (2014). http://dx.doi.org/10.1016/j.jpowsour.2013.09.103.

9. H. Wang, M. Gu, J. Jiang, C. Lai, X. Ai, An O3-type NaNi0.5Mn0.3Ti0.2O2 compound as new cathode material for room-temperature sodium-ion batteries, Journal of Power Sources, 327 (2016). https://doi.org/10.1016/j.rser.2016.09.011.

10. S.-W. Kim, D.-H. Seo, X. Ma, G. Ceder, K. Kang, Electrode Materials for Rechargeable Sodium-Ion Batteries: Potential Alternatives to Current Lithium-Ion Batteries. Advanced Energy Materials, 2 (2012). http://dx.doi.org/10.1002/aenm.201200026.

11. J. Schnell, T. Günther, T. Knoche, C. Vieider, L. Köhler, A. Just, M. Keller, S. Passerini, G. Reinhart, All-solid-state lithium-ion and lithium metal batteries - paving the way to large-scale production, Journal of Power Sources, 382 (2018). https://doi.org/10.1016/j.jpowsour.2018.02.062.

12. H. Liu, Z. Wei, W. He, J. Zhao, Thermal issues about Li-ion batteries and recent progress in battery thermal management systems: A review, Energy Conversion and Management, 150 (2017). https://doi.org/10.1016/j.enconman.2017.08.016.

13. K. M. Winslow, S. J. Laux, T. G. Townsend, A review on the growing concern and potential management strategies of waste lithium-ion batteries, Resources, Conservation and Recycling, 129 (2018). https://doi.org/10.1016/j.resconrec.2017.11.001.

14. Z. Guirong, Z. Henghai, L. Houyu, The Driving Control of Pure Electric Vehicle, Procedia Environmental Sciences, 10(A) (2011. https://doi.org/10.1016/j.proenv.2011.09.071. 
15. L. Lu, X. Han, J. Li, J. Hua, M. Ouyang, A review on the key issues for lithium-ion battery management in electric vehicles, Journal of Power Sources, 226 (2013). https://dx.doi.org/10.1016/j.jpowsour.2012.10.060.

16. Thomas A. Stuart, W. Zhu, Modularized battery management for large lithium ion cells, Journal of Power Sources, $196 \quad$ (1) https://dx.doi.org/10.1016/j.jpowsour.2010.04.055.

17. M. Zackrisson, L. Avellán, J. Orlenius, Life cycle assessment of lithium-ion batteries for plug-in hybrid electric vehicles - Critical issues, Journal of Cleaner Production, 18 (15) (2010). https://dx.doi.org/10.1016/j.jclepro.2010.06.004.

18. S. Pelletier, O. Jabali, G. Laportea, M. Veneroni, Battery degradation and behaviour for electric vehicles: Review and numerical analyses of several models, Transportation Research Part B: Methodological, 103 (2017). https://doi.org/10.1016/j.trb.2017.01.020.

19. J. Zhu, T. Wierzbicki, W. Li, A review of safety-focused mechanical modeling of commercial lithium-ion batteries, Journal of Power Sources, 378 (2018). https://doi.org/10.1016/j.jpowabadasour.2017.12.034.

20. S. Abada, G. Marlair, A. Lecocq, M. Petit, V. Sauvant-Moynot, F. Huet, Safety focused modeling of lithium-ion batteries: A review, Journal of Power Sources, 306 (2016). https://doi.org/10.1016/j.jpowsour.2015.11.100.

21. J. Ordoñez, E.J. Gago, A. Girard, Processes and technologies for the recycling and recovery of spent lithium-ion batteries, Renewable and Sustainable Energy Reviews, 60 (2016). https://doi.org/10.1016/j.rser.2015.12.363.

22. B. Homan, M. V. ten Kortenaar, J. L. Hurink, G. J. M. Smit, A realistic model for battery state of charge prediction in energy management simulation tools, Energy, 171 (2019). https://doi.org/10.1016/j.energy.2018.12.134.

23. D. Grazioli, M. Magri, A. Salvadori, Computational modeling of Li-ion batteries, $\begin{array}{lllll}\text { Computational } & \text { Mechanics, } & 58 & \text { (6) }\end{array}$ https://link.springer.com/article/10.1007\%2Fs00466-016-1325-8. 
24. R. Suresh, H. K. Tanneru, R. Rengaswamy, Modeling of rechargeable batteries, Current Opinion in Chemical Engineering, $13 \quad$ (2016). https://doi.org/10.1016/j.coche.2016.08.005.

25. M. Doyle, T. F. Fuller, J. Newman, Modeling of galvanostatic charge and discharge of the lithium/polymer/insertion cell, Journal of the Electrochemical Society, 140 (6) (1993). https://doi.org/10.1149/1.2221597.

26. J. Li, L. Wang, C. Lyu, E. Liu, Y. Xing, M. Pecht, A parameter estimation method for a simplified electrochemical model for Li-ion batteries, Electrochimica Acta, 275 (2018). https://doi.org/10.1016/j.electacta.2018.04.098.

27. C. Yi-Hsien, S. Wu-Yang, K. Jia-Cheng, Online estimation of internal resistance and open-circuit voltage of lithium-ion batteries in electric vehicles, Journal of Power Sources, 196 (2011). https://doi.org/10.1016/j.jpowsour.2011.01.005.

28. X. Lai, Y. Zheng, T. Sun, A comparative study of different equivalent circuit models for estimating state-of-charge of lithium-ion batteries, Electrochimica Acta, 259 (2017). https://doi.org/10.1016/j.electacta.2017.10.153.

29. J. Jaguemont, A. Nikolian, N. Omar, P. Van Den Bossche, and J. Van Mierlo, Development of a 2D-thermal model of three battery chemistries considering entropy, IEEE Transactions on Energy Conversion, $32 \quad$ (4) (2017). http://dx.doi.org/10.1109/TEC.2017.2697944.

30. J. Park, W. A. Appiah, S. Byun, D. Jin, M-H. Ryou, Y. M. Lee, Semi-empirical long-term cycle life model coupled with an electrolyte depletion function for large-format graphite/LiFePO4 lithium-ion batteries, Journal of Power Sources, 365 (2017). http://dx.doi.org/10.1016/j.jpowsour.2017.08.094.

31. Q.-K. Wang, Y.-J. He, J.-N. Shen Z.-F. Ma, G.-B. Zhong, A unified modeling framework for lithium-ion batteries: An artificial neural network based thermal coupled equivalent circuit model approach, Energy, 138 (2017). http://dx.doi.org/10.1016/j.energy.2017.07.035. 
32. A. J. Salkind, C. Fennie, P. Singh, T.I Atwater, D. E. Reisner, Determination of state-ofcharge and state-of-health of batteries by fuzzy logic methodology, Journal of Power Sources, 80 (1999).

33. F. Saidani, F. X. Hutter, R.-G. Scurtu, W. Braunwarth, J. N. Burghartz, Lithium-ion battery models: a comparative study and a model-based powerline communication, Advances in Radio Science, 15 (2017). https://doi.org/10.5194/ars-15-83-2017.

34. K. Thirugnanam, H. Saini, P. Kumar, Mathematical Modeling of Li-lon Battery for Charge/Discharge Rate and Capacity Fading Characteristics using Genetic Algorithm Approach, Transportation Electrification Conference and Expo (ITEC), (2012). https://doi.org/ 10.1109/ITEC.2012.6243431.

35. S. Zhang, K. Zhao, T. Zhu, J. Li, Electrochemomechanical degradation of high-capacity battery electrode materials, Progress in Materials Science, 89 (2017). https://doi.org/10.1016/j.pmatsci.2017.04.014.

36. M. Möller, C. Glocker, Non-smooth modelling of electrical systems using the flux approach, Nonlinear Dynamics, 50 (2007). https://doi.org/10.1007/s11071-006-9157-2.

37. L. Prandtl, Ein Gedankenmodell zur kinetischen Theorie der festen Körper, Journal of Applied Mathematics and Mechanics, 8 (2) (1928). https://doi.org/10.1002/zamm.19280080202.

38. M. Nagode, F. Zingsheim, An online algorithm for temperature influenced fatigue-life estimation: strain-life approach, International Journal of Fatigue, 26 (2003). https://doi.org/10.1016/S0142-1123(03)00108-7.

39. M. Nagode, M. Hack, M. Fajdiga, Low cycle thermo-mechanical fatigue: damage operator approach, Fatigue \& Fracture of Engineering Materials \& Structures, 33 (3) (2009). http://dx.doi.org/10.1111/j.1460-2695.2009.01424.x.

40. F. Preisach, Zeitschrift für Physik, 94, 5-6 (1935), https://doi.org/10.1007/BF01349418.

41. M. Nagode, M. Hack, M. Fajdiga, High cycle thermo-mechanical fatigue: Damage operator approach, Fatigue \& Fracture of Engineering Materials \& Structures, 32 (2009). https://doi.org/10.1111/j.1460-2695.2009.01353.x. 
42. A. Gosar, M. Nagode, Energy dissipation under multiaxial thermomechanical fatigue loading, International Journal of Fatigue, $48 \quad$ (2013). https://doi.org/10.1016/j.jifatigue.2012.10.021.

43. M. Nagode, D. Šeruga, Fatigue life prediction using multiaxial energy calculations with the mean stress effect to predict failure of linear and nonlinear elastic solids, Results in Physics, 6 (2016). https://doi.org/10.1016/j.rinp.2016.06.007.

44. S. Goutam, J. M. Timmermans, N. Omar, P. Van den Bossche, and J. Van Mierlo, Comparative study of surface temperature behaviour of commercial li-ion pouch cells of different chemistries and capacities by infrared thermography, Energies, 8 (8) (2015). https://doi.org/10.3390/en8088175.

45. A. Nikolian, Y. Firouz, R. Gopalakrishnan, J.-M. Timmermans, N. Omar, P. V.D. Bossche, J. V. Mierlo, Lithium Ion Batteries-Development of Advanced Electrical Equivalent Circuit Models for Nickel Manganese Cobalt Lithium-Ion, Energies, 9 (5) (2016). https://doi.org/10.3390/en9050360.

46. L. Zhang, H. Peng, Z. Ning, Z. Mu, C. Sun, Comparative Research on RC Equivalent Circuit Models for Lithium-Ion Batteries of Electric Vehicles, Applied Sciences, 7 (10) (2017). https://doi.org/10.3390/app7101002.

47. Z. Gao, C. S. Chin, W. L. Woo, J. Jia, Integrated Equivalent Circuit and Thermal Model for Simulation of Temperature-Dependent LiFePO4 Battery in Actual Embedded Application, Energies, 10, 1 (2017). https://doi.org/10.3390/en10010085.

48. S. Tong, M. P. Klein, J. W. Park, On-line optimization of battery open circuit voltage for improved state-of-charge and state-of-health estimation, Journal of Power Sources, 293 (2015). http://dx.doi.org/10.1016/j.jpowsour.2015.03.157.

49. A. Nikolian, J. Jaguemont, J. de Hoog, S. Goutam, N. Omar, P. V.D. Bossche, J. V. Mierlo, Complete cell-level lithium-ion electrical ECM model for different chemistries (NMC, LFP, LTO) and temperatures $\left(-5^{\circ} \mathrm{C}\right.$ to $\left.45^{\circ} \mathrm{C}\right)$ - Optimized modelling techniques, International Journal of Electrical Power \& Energy Systems, 98 (2018). https://doi.org/10.1016/j.jiepes.2017.11.031. 
50. F. Millo, C. Cubito, L. Rolando, E. Pautasso, E. Servetto, Design and development of an hybrid light commercial vehicle, Energy, $136 \quad$ (2017). https://doi.org/10.1016/j.energy.2016.04.084

51. M.Tutuianu, P. Bonnel, B. Ciuffo, T. Haniu, N. Ichikawa, A. Marotta, J. Pavlovic, H. Steven, Development of the World-wide harmonized Light duty Test Cycle (WLTC) and a possible pathway for its introduction in the European legislation, Transportation Research Part D: Transport and Environment, $40 \quad$ (2015). https://doi.org/10.1016/j.trd.2015.07.011. 